Article

\title{
How Ecocentrism and Anthropocentrism Influence Human-Environment Relationships in a Kenyan Biodiversity Hotspot
}

\author{
Jana Rülke ${ }^{1}$, Marco Rieckmann ${ }^{2}\left(\mathbb{D}\right.$, Joslyn Muthio Nzau ${ }^{3}$ and Mike Teucher ${ }^{4, *(\mathbb{D}}$ \\ 1 Economic Geography, Institute of Geography, School of Cultural Studies and Social Sciences, University of \\ Osnabrueck, Seminarstr. 19 a/b, D-49074 Osnabrueck, Germany; jana.ruelke@uni-osnabrueck.de \\ 2 Department of Education, Faculty of Education and Social Sciences, University of Vechta, Driverstraße 22, \\ D-49377 Vechta, Germany; marco.rieckmann@uni-vechta.de \\ 3 Terrestrial Ecology Research Group, Department of Ecology and Ecosystem Management, Technical \\ University Munich, Hans-Carl-von-Carlowitz-Platz 2, D-85354 Freising, Germany; muthio.nzau@tum.de \\ 4 Institute of Geoscience and Geography, Department of Geoecology, Martin Luther University \\ Halle-Wittenberg, Von-Seckendorff-Platz 4, D-06099 Halle (Saale), Germany \\ * Correspondence: mike.teucher@geo.uni-halle.de
}

Received: 21 August 2020; Accepted: 1 October 2020; Published: 5 October 2020

\begin{abstract}
Protecting nature and securing human livelihood needs are very conflicting especially in biodiversity-rich areas of the Global South. The Taita Hills Cloud Forest (THCF) in Kenya remains one of the top biodiversity hotspots worldwide. Environmental data for the area has been studied for decades. Sociodemographic analyses on inequality have been conducted by governmental and non-governmental organizations. Little has been done yet to correlate them to investigate their relationships. A lot of attention has been paid to the connection between agricultural practices and impacts on the environment, but human-environment relationships are much more complex, especially in Kenya's biodiversity-rich areas. This paper assesses the local population's perception of its surrounding environment and investigates their understanding of nature conservation. Using quantitative and qualitative methods, 300 survey respondents were classified concerning their nature ethical views (particularly anthropocentrism and ecocentrism). By using grounded theory, data were regularly reviewed during the entire research, to assemble an evaluable and comparable dataset. Our study reveals that gender has a distinct impact on whether the interviewees have an anthropocentric or ecocentric perspective of nature and conservation. Moreover, there is a strong need for an intermediate bridge between anthropocentrism and ecocentrism.
\end{abstract}

Keywords: human-environment relationships; nature conservation; Taita Hills; biodiversity hotspot; ecocentrism; anthropocentrism; human-government conflicts

\section{Introduction}

In the Anthropocene period, the world setting seems a dichotomy of ecology and humanity, nature and people [1,2]. The interrelationships between humankind and nature are as heterogeneous and complex as nature itself. Nature and humankind are continuously influencing each other. The way in which each individual or whole societies perceive nature, the external influences affecting them, and how they deal with them are diverse and impinged by many factors. Talking about human-environment relationships means to ask which humans and which environment are taken into account. The reasons are that nature and environment differ around the globe and so do the impacts and circumstances for the people living in these spaces [3]. Thus, it is tremendously important to identify exactly which people and which environment are meant, since these facts define the relationship in an individual way. 
However, are ecology and humanity really that incompatible? Can human beings and the environment coexist any longer? Or, more explicitly: can the human livelihood be secured and developed while protecting nature? These are the topics analyzed by anthropogeography and human-environment relationships, which is an interdisciplinary research area and investigates these relationships in detail [4]. To ensure respectful and peaceful coexistence for the entirety of people and nature, it is relevant to understand the issues on both sides. Beyond the point of assured needs, the opportunity arises to do more, to contribute to oneself and to other human beings, as well as to other life forms.

Among the different types of centrism stated in literature [5,6], two are used in this study, anthropocentrism and ecocentrism, which differ in the core. While an anthropocentric mindset predicts a moral obligation only towards other human beings, ecocentrism includes all living beings. Whether a person prescribes to anthropocentrism or ecocentrism influences the perception of nature and its protection and, therefore, has an effect on the nature-related attitude [5-11]. To develop a deeper understanding of these relationships, a survey was conducted and an attempt was made to allocate the respondents' answers to anthropocentrism or ecocentrism. Therefore, the answers to binary questions were analyzed and, in the following, the answers to the open questions were evaluated. This process is important because a simple "yes" or "no" as an answer is not enough for the interpretation of whether someone's mindset belongs to anthropocentrism or ecocentrism. The "why" is more important. To gain an understanding of complex interconnections and heterogeneous social relationships, including human-environment relationships, and in order to develop sustainable recommendations, we used the approach of grounded theory (GT) [12]. GT is an interactive-cyclical progression which describes the whole research process: certainty $\rightarrow$ doubt $\rightarrow$ testing $\rightarrow$ certainty [13]. Pragmatism plays a role in GT, as it does in the transformation from an environment to a living world in anthropogeography [13-15], as well as in environmental ethics $[5,16,17]$. Pragmatism does not take reality as a given. It does not even assume that there is one reality and, thus, it fits into the context of the study and its heterogeneity and development [18]. Thus, it supports the investigation of the why, as mentioned above.

The Taita Hills in southern Kenya $\left(3^{\circ} 25^{\prime} S 38^{\circ} 20^{\prime}\right.$ E) are characterized by a mosaic of different land use types, consisting of small patches of natural cloud forest, plantations of exotic trees (pine, cypress, and eucalyptus, mostly), agricultural land (crop fields with gardens), and settlements $[19,20]$. Rapid transformation of the original cloud forest into the current ecosystem mosaic started already during the pre-colonial era, about 200 years ago, and continues until today [21,22]. Agricultural intensification due to "favourable climatic and edaphic conditions" [23] (p. 167) combined with local high population density exacerbate environmental pressure and degradation progressively contributing to deforestation, habitat loss, and biodiversity loss [23-26]. The Taita Hills region is currently faced with great local complexities that are influenced by many different factors, such as the colonial period that the country and the region endured, the numerous postcolonial developments, competing socio-cultural influences, demographic developments, emerging conflicts and uncertainties, and the effects of climate change.

This paper focuses on complex human-environment relationships in the central part of the biodiversity hotspot, the Taita Hills Cloud Forest (THCF), in southern Kenya. We investigate the motivations and understandings of the rural population for nature conservation. The pivotal research questions are as follows:

1. Which factors influence the understanding of nature of the rural population in the THCF?

2. Which humans are meant and which environment is worth being protected?

3. What factors influence an ecocentric or anthropocentric mindset?

\subsection{State of the Art}

Human-environment relationships are a classical research subject in anthropogeography, but they are also part of many different disciplines, approaches, and theories (e.g., [4,6,14,15,27-30]). Interdisciplinary and transdisciplinary approaches were pursued in respect of further developments. Nevertheless, the most significant discoveries will be considered as an introduction to the paradigm change, 
taking the environment into account. Anthropogeography as part of general geography deals with the space effectiveness of humans and the anthropogenic influences on their surrounding environment [31].

Human-environment sciences including geography, (human-)ecology, and ethics and philosophy are as old as humanity itself [15]. That is why there are many diverse, complex, and differing concepts of society-environment-systems [27], human-environment systems [28], human-environment comprehension [14], human-environment relation [4], human-nature relation [29], human-nature relationships [6], nature-society relationships [30], human/nature interaction [32], human-non-human world relations [33], society-environment relationships [34], and some other relationship studies and theories. Despite their heterogeneous research approaches resulting from their diverse research disciplines, they all seek to transcend the dualistic perspective of human-environment relationships and to provide an inclusive view of all life on earth and their interconnection. The perspective of the "Human-Living Planet-Geography" [15], (p. 248) takes a pragmatic, transactive, and holistic perspective to close the gap between the sharp division of human society within the environment [28]. Therein, the concept of environment depends on the individual mindset and the discipline in which the word is used [35]. While in ecology, general system theory, and general geography, environment means the "physical, measurable and perceptibly surroundings" [31] (p. 91), in sociological system theory, environment is everything which is not part of the system [36]. Luhman splits the social reality into three types of separate systems (psychological, biological, and social) [36-38]. His paradigm is that everything can only exist and be valid in relationship to something and conversely, to itself. Through this reciprocal dynamic and the flow of all entities, Luhmann's approach becomes very complex and multifaced, with the focus always on defining the environment by its relationship. Popper also takes this view and defines three worlds [39]. World I is that of physical and material things and symbolizes nature, states of consciousness form World II, and World III is the social world. For him, too, the relationships between the worlds were at the heart of this system theory [39]. System theory plays a key role in studying the relationships between human beings and their environment in all disciplines dealing with this system $[16,29,32,34,38,40-44]$.

In the view of Weichhart, general geography would be better able to deal with human-environment relationships if it could find a way to reunite physical and human geography as a combined science [45]. Since geography itself thematizes space, place, and scale with different flows as quintessential theories, the relations between humans and nature, society and environment, all become part of a space question.

Whaley takes the theme of this classical geographical concept to another level and contemplates it, inter alia, from a "natural inclusionality" perspective [3] (p. 32). In addition to human geography, he also employs philosophy, psychology, social science, and phenomenology to bring Rayner's philosophy of natural inclusionality [46] (p. 55) into an interdisciplinary encounter space, in order to confront existing space concepts, established logics, and different interpretations of the self. In doing so, he warns that ultimate definitions create limitations and flow into a global society of exclusion, as well as the constant otherness, since self-definition occurs over the demarcation. Today, space is detached from place, which represents the world's diversity and complexity, as well as a self (with all its mindsets, actions, relations, etc.) and has different starting and reference points, reflecting the variety of beings. Conversely, this could mean that space and self could lead to a commonality rather than splitting, independently of how this individual space is shaped.

Glaeser and Teherani-Krönner describe the interaction between human and cultural ecologies as the most comprehensive way of capturing human-environment relationships [47]. Due to the interest in the understanding of these two types of social ecology and their different divergences and alignments, a transdisciplinary research approach allows a view from another perspective [47].

Since numerous attempts have failed to unite the many different theories and disciplines surrounding the relationship between societies and the environment, it has been difficult to grasp the nature of these environments. Considering the many different definitions and applications of the word nature and everything related to it, there is no universally accepted concept of nature. Everyone uses the word nature differently (similar to the term environment of which nature is part) and has different ideas 
and thoughts in mind for the abstract concept of nature. One definition is that everything which exists independently (also of time) by itself and is not created by humans can be called nature or natural [48]. Furthermore, nature can be divided into living nature and not living nature [16]. While an obsolete understanding only separated nature into plants and animals, nowadays it is divided into biotic or abiotic. Animals, plants, fungi, and microorganisms represent biotic nature, while mountains, oceans, air, water, soil, clouds, stars, and so on, belong to the abiotic nature. Following this logic, humans are not part of nature. There is nature and there are human beings and they are connected in a human-nature system. The parts of every system are connected, and this connectedness creates relationships.

Since the transition from an environment to a living planet has been made, from now on the living planet is meant when environment is written. Due to the common use of the term environment in human-environment relationships, it still will be used but the meaning of the living planet should be evident.

\subsection{Ecocentrism and Anthropocentrism}

Anthropocentrism, pathocentrism, biocentrism (ecocentrism), and holism (cosmocentrism) are the four main types of environmental ethics [5-7], which "can be defined [ ... ] as efforts to articulate, systematize, and defend systems of value guiding human treatment of and behaviour in the natural world." [8] (p. 597).

The division into the different types of environmental ethics ensues from the question of value-conferring principles. While anthropocentrism stands by itself, patho- and biocentrism, as well as holism, are parts of physiocentrism [6]. It is always a question of ethical relevance and, therefore, a case of allocation to the different centrism. Human beings' moral obligation towards their fellow human beings is the core component of anthropocentrism. Pathocentrism goes to the extent of assigning an inherent value to all natural beings capable of suffering. However, biocentrism grants all living beings "a moral status regardless of their organizational level." [5] (p. 22). According to Gorke, the proponents of patho- and biocentrism are divided due to the discussion of controversial concepts of hierarchical or egalitarian centrism [5].

Whether an eco(bio-)centric or anthropo(ego-)centric moral reasoning or perspective is adopted is part of the question of how humans perceive and interrelate with nature [49].

Sometimes it appears impossible that these opposites can exist and lay a claim to their right to existence: human and environment, society and nature, human and non-human life, development and conservation, and anthropocentrism and ecocentrism $[9,10]$. However, for both Eser and Schweitzer, the attachment to nature (physiocentrism) is something inherent in human beings [9-11]. The UN also states that humans have a right to live a (healthy and productive) life in harmony with nature [50]. The question of an anthropocentric or ecocentric approach can also be asked here: Why do we protect nature? Because we love nature or because we need it? Because nature has a right to exist by itself or because we can use it to benefit us? This has been much discussed in terms of natural and environmental ethics [7,11,40,48,49,51-55].

Nature in the sense of the environment is understood in this paper to be the floristic and faunistic entirety. Thus, the THCF and its plants and animals, with all its ecosystem services and dynamics, regardless of whether they can be used by humankind or not, are considered [17].

Concerning the section above and prior mentioned research questions, the following hypotheses were formulated based on previous research in this field:

4. The respondent's age and education influence their appreciation and perceptions of nature.

5. The population in the study area has a greater knowledge of plants than animals.

6. Better situated respondents with greater land size are more willing to protect plants and animals around the THCF.

7. There is a higher percentage of anthropocentric-reasoning people than ecocentric ones. 


\section{Materials and Methods}

The study was conducted in the surroundings of the THCF, a mountain range rising sharply from dry lowlands and savannas at 600 to 900 mamsl, to a maximum of 2208 mamsl, partly covered by Afromontane cloud forest [23,56]. They resemble green, fertile islands in an ocean of drought [24]. The highest peak is named Vuria and the semi-arid surroundings are dominated by Acacia and Commiphora shrubland and dry savannas [23]. Due to its geographical position, there is a bimodal rainfall pattern [24,56-58]. The two annual rainy seasons are a longer season from March to May, sometimes June, and a shorter one in November and December, sometimes beginning in October [57]. The average annual rainfall amount of $1328 \mathrm{~mm}$ is constituted by $589 \mathrm{~mm}$ during the first rainy season and $496 \mathrm{~mm}$ in the shorter period, on average [57]. Climatic and edaphic conditions are the main reasons why the Taita Hills belong to the top ten biodiversity hotspots in the world $[23,59]$. In areas with mentioned rainy seasons and with the highest soil fertility in the region, the farmers adopted their farming practices [58,60]. Thus, as in Kenya generally, agriculture is also the backbone of the Taita people [25].

Starting from the agricultural campus of the Taita Taveta University in Ngerenyi [61], survey locations were identified, as shown in Figure 1. The surveys were conducted between Ngerenyi in the north and Chawia in the southwest.

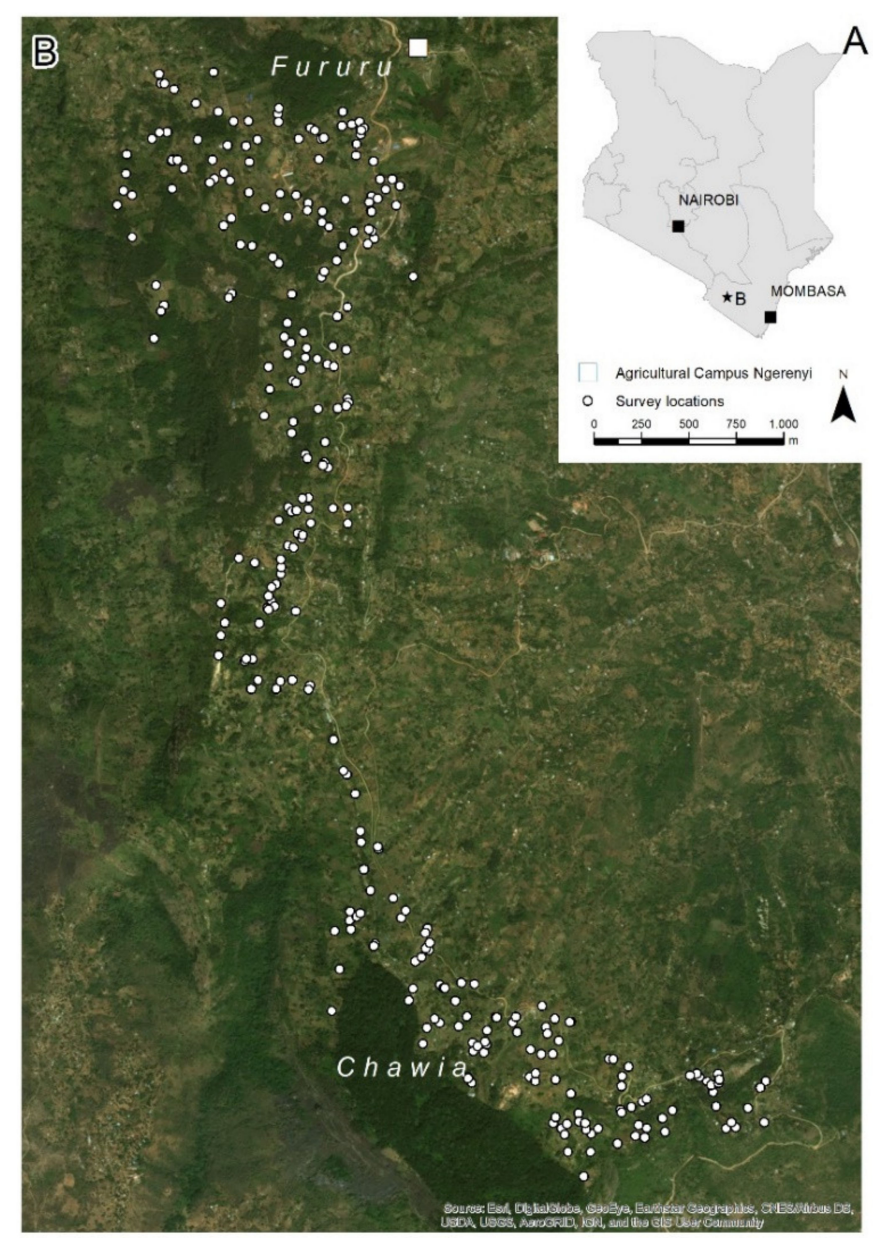

Figure 1. Interview locations displayed as white dots within the study area. Taita Taveta University Agricultural Campus is indicated as white square (own illustration).

The human-environment relationships in the Taita Hills were studied using the approach of GT. Accordingly, a theoretical sampling and a three-stage coding were carried out [62]. The classical, qualitative mixture of methods, which is a characteristic of GT, was extended by a quantitative 
component. Through the combination of qualitative and quantitative survey and evaluation methods, reproducibility was ensured.

The quantitative data collection was done by establishing and applying a standardized questionnaire which is based on the earlier work of Nzau et al., and was adjusted to the local complexities of the THCF [63]. This questionnaire was structured into six sections and contained a total of 43 questions, including 17 open questions. These 17 open questions were always connected to a binary question and provided an opportunity for the respondents to explain their answers to binary questions. The socio-demographic data and side conditions were captured using nine questions in section one, while 10 questions in part two were used to depict the components of culture, indigenous knowledge, and conservation. Part three referred to land tenure and use, with two questions and part four contained 12 questions about environmental awareness and attitudes. One question with several sub-questions, to be answered using a Likert-scale, asked for several aspects of willingness to contribute. Nine questions were asked in the last and sixth part of the questionnaire about environmental habits. The open questions could be used for a qualitative analysis. Overall, 300 standardized surveys were conducted, and the participants were determined by theoretical sampling, due to the use of GT. In addition, a GPS point was recorded at the end of every interview. The questionnaire was bilingual: it had been translated from English into Swahili. Data acquisition was performed using Open Data Kit (ODK) Collect and a Samsung tablet device (details see Supplementary Materials S2). ODK is a software for data acquisition and administration which provides an open source app for working independently of network connections in remote areas. Two pre-tests were performed, each with a time of 25 to $50 \mathrm{~min}$ per interview. These pre-tests were conducted to identify difficulties or mistakes ex ante so they could be eliminated before the actual interviews began.

The qualitative data came from four sources: 100 semi-structured observation protocols, a 30-day field diary, 17 answers to the open questions in the above-mentioned standardized questionnaire, and six semi-structured expert interviews.

The 100 semi-structured observation protocols are ethnographic observations made on-site during the quantitative surveys. The advantage of structured or semi-structured observations is that they can then be reliably compared and analyzed [64]. This framework was created to summarize suggestions from the literature, which are usually taken into account during observations [65-68]. Post-processing, transmission, and digitization took place daily, so that no impressions would be forgotten and so that the handwritten notes could be reproduced as comprehensively and as completely as possible. The 100 observations were made at six different locations in the Taita Hills: Ngerenyi (12), Saghaighu (18), Susu (8), Lagho (11), Bura (9), and Chawia (42). In the field, as well as later during the analysis, the observation protocols and questionnaires were paired because of the proximity of observation and questioning.

The field diary was prepared daily to record further subjective impressions, in addition to those already recorded in the observation protocols. This is a method that is used only when method constraints should be left out [69]. To capture the many impressions and significant influences in a variety of ways, we enriched qualitative and quantitative data collection by incorporating the field diary.

In addition, six semi-structured expert interviews with four sections and a total of 19 questions were conducted. The interviews among officials from governmental and non-governmental agencies began with a general question about the interviewee's position, followed by questions directly related to the forest, e.g., about the locals' interactions with the forest and the goods that are produced around or in the forest. Questions about management and protection issues were asked in part three. At the end, the interviewees were asked about their personal ideas, as well as about religion and gender and their effects on nature conservation. Due to the interviewees' different jobs, positions, and knowledge, not all questions were asked in every interview. Handwritten notes were made during all the interviews, which were then compiled and completed. This resembles a summary protocol [70]. Only two interviews were recorded and transcribed literally into written English, without consideration 
of special accents or sounds [70]. Four of the expert interviews were conducted in English and two in Swahili.

The data obtained during the 2018 survey were statistically analyzed using the program IBM SPSS version 25 to obtain information about distributions, frequencies, dependencies, or relationships between the derived variables [71]. The data collected from the surveys were mainly ordinal or nominal, more rarely metric. Therefore, where possible, an attempt was made to convert nominal variables into ordinal or metric quantities to operationalize them. Responses of the interviewees are included in Supplementary Materials Table S1 and will be referenced in brackets.

Some questions were divided into a closed question and a supplementary, open sub-question, so that while yes, no, or don't know could be selected for the first part, it was possible to explain this answer in the second part. In addition, scale levels and categories were assigned to uniform numbering systems and 38 new variables were created by re-coding of existing variables, including records of observation protocols, or came from two exploratory factor analyses. The latter were performed once for the entire dataset and for which both the answered questionnaire and the observation protocols were conducted according to Bühl and Backhaus using Kaiser-Meyer-Olkin criteria (KMC) and scree plot analysis [72,73]. Two exploratory factor analyses were conducted and of the original 173 variables in the adjusted questionnaire, 66 could be disregarded for the factor analysis of the entire set of variables due to the results of the anti-image covariance matrix method. The selection was this extensive so that as many aspects and facets as possible could be considered meaningfully because human-environment relations are a very complex, multi-layered structure, which cannot be explained one-dimensionally. Which variables were grouped together to form factors is shown in Appendix A, Figure A1 and Table A in Supplementary Materials S2. A mathematically founded selection of the variables' explanatory power was made based on KMC, which analyzes the measure of sampling adequacy (MSA). Seven factors were formed from a total of 40 variables which had an MSA-value $\geq 0.6$, and an eigenvalue of Kaiser criterion $\geq 1$. The extracted factors explained $43.7 \%$ of the variance using varimax rotation and KMC. In contrast to the factor analysis for the entire dataset, three more variables were used to analyze one-third of it. These additional variables were derived from the observation protocols. For the second factor analysis, 110 variables remained for which eight factors were formed from a total of 43 variables, explaining $54.6 \%$ of variance using the same rotation methods as above (for details see Appendix A, Figure A2 and Table B in Supplementary Materials S2).

While factor analysis was used to filter out the most appropriate variables from the entire dataset and to aggregate them into factors, the variances in the explicit hypotheses for answering the research questions were addressed using Analysis of Variance, the Welch ANOVA and subsequent Games-Howell post-hoc tests or Bonferroni post-hoc test to counteract the multiple comparison problem [74]. In addition, whenever appropriate, cross tabulations, Chi-square tests, nonparametric correlations and tests, F-tests, and multivariate general models were applied.

Qualitative analyses were performed according to GT with MAXQDA version 18 [75]. The qualitative data were stepwise analyzed by creating codes, categories, and concepts in accordance with the use of GT that corresponded to the main interest of human-environment relationships. The entire dataset (semi-structured observation protocols, field diary, answers to the open questions in the questionnaire, and semi-structured expert interviews) was analyzed. The analyses of human-environment relationships started with the observation protocols. The subsequent blending with the questionnaires was done to provide a more complete picture, which was supplemented by the expert interviews and the field diary. While the main codes were formulated deductively, due to the protocols' established semi-structured schema, the codes based on them were developed inductively. All 100 observation protocols were processed in this way. According to GT, three different and mutually constructive codings were conducted (open, axial, and selective coding) [13,62]. In terms of theory formation, categories were defined based on the codes that were formed to identify a phenomenon and related cases. Thus, a code system with 153 codes was established and 2806 codings were placed within the 100 observation protocols and the associated questionnaires. Eight categories were defined 
according to the structure of the observation protocols, including the location, the researchers present, and some of the interviewees' original statements. Furthermore, the questions which attracted the researcher's attention, due to longer explanations or discussions between the interviewee and the interviewer, or statements made by the interviewee, also got a code, e.g., question 24 Should plants and animals be protected? were of tremendous importance and, thus, was given twelve extra codes.

\section{Results}

In this section, the results are presented according to the research questions.

\subsection{Which Factors Influence the Understanding of Nature of the Rural Population in the THCF?}

To answer the first research question and associated hypothesis, the underlying idea was to find out what influences the understanding of nature by analyzing the factor appreciation and perception of nature. By using a univariate ANOVA, the variances were analyzed in relation to the independent variables age and level of education. The variance homogeneity was checked using Levene's test, which shows that it cannot be assumed, either for age $(p=0.016)$ or for level of education $(p<0.001)$. The analysis revealed that although age did not have a significant overall impact on the factor appreciation and perception of nature, there was a specific significant difference between the age groups " 29 to 39 " and "62 and older" tested by Games-Howell (+/-0.549, 95\%-CI [+/-1.10, 0.00], $p=0.050)$.

The measures of effect size were small $\left(\eta^{2}=0.039, \omega^{2}=0.026, \varepsilon^{2}=0.026\right)$. By using a Welch ANOVA, a significant result could be identified for the independent variable level of education $(6,7.058)=72.168$, $p<0.001$.

This indicates that this variable had a highly significant influence on the factor appreciation and perception of nature. The Games-Howell showed significant differences between the following groups:

- $\quad$ none $\leftrightarrow$ primary complete $(+/-0.918,95 \%-\mathrm{CI}[+/-1.74,+/-0.10], p=0.020)$

- $\quad$ none $\leftrightarrow$ secondary complete $(+/-1.031,95 \%-\mathrm{CI}[+/-1.89,+/-0.17], p=0.010)$

- none $\leftrightarrow$ university $(+/-1.475,95 \%-\mathrm{CI}[+/-2.51,+/-0.44], p=0.002)$

- $\quad$ primary incomplete $\leftrightarrow$ primary complete $(+/-0.678,95 \%-\mathrm{CI}[+/-1.15,+/-0.21], p=0.001)$

- $\quad$ primary incomplete $\leftrightarrow$ secondary complete $(+/-0.792,95 \%-\mathrm{CI}[+/-1.34,+/-0.24], p=0.001)$

- $\quad$ primary incomplete $\leftrightarrow$ university $(+/-1.235,95 \%-\mathrm{CI}[+/-2.08,+/-0.39], p=0.002)$

- The measures of effect sizes were medium to large $\left(\eta^{2}=0.145, \omega^{2}=0.126, \varepsilon^{2}=0.126\right)$.

The more the level of education differed, the higher and more significant this difference became. If appreciation and perception of nature are equated with people engaging themselves for the protection of nature because of their own interests and motives, and without a monetary incentive or being compelled to do so, then the statements from the expert interviews can be interpreted accordingly. For instance, in interview number five (I5), with the Susu Ndiweni Fururu Community Forest Association (SuNdiFu CFA), the respondents described how the situation had changed during the last 20 years due to anthropogenic influences and named some causes, such as forest fires and illegal logging (I5, lines 12-21, 23-24, 33-47, 259-263). They recognized the ongoing loss of biodiversity and the urgent need to become active (I5, lines 12-15). This was also confirmed by interview partner number one (I1), from Furaha's Women's Group (I1, lines 32-38). They formed their group due to their common interest in doing something for nature conservation, without external pressure to do so and without the aim of doing it for monetary benefit (I1, lines 41-44). Something similar was reported by interviewee number two (I2), from Ecotourism Kidaya, who described the reason for group formation as: "Trying to organize the heritage value of the county and to bring all the value of Taita in layout strategy." (I2, lines 14-15). The work of the different groups and the Community Forest Associations (CFAs) is well appreciated and needed by Nature Kenya Wundanyi (I4) but, as the respondent explained, there are sometimes difficulties due to misunderstandings, inadequate communication, and own dynamics. He recounted a situation with a CFA within the Ngerenyi area which is seeking to expand their association and motivate their members to grow seedlings for sale. 


\subsection{Which Humans Are Meant and Which Environment Is Worth Being Protected?}

The question of which humans and which environment are meant cannot be answered with a short, very general answer. If the respondents are assumed to be individual elements of the given population, it can be said that, on average, they have some aspects in common: they are mainly Christians (99\%), they live fairly close to the THCF, they depend on subsistence and small-scale farming, and almost $85 \%$ of them have a monthly income below 10,000 Kenyan shillings (KSh). Nevertheless, the population is quite heterogeneous in almost every other aspect (level of education, number of children in household, type of housing, access to water, etc.).

Dealing with this question, people's knowledge of the surrounding species was evaluated. Several crosstabs were calculated to analyze the differences between the knowledge of plants and animals and the significances were tested with Chi-square by Pearson. The intersection of the two questions Are there endangered plants in this area? and Are there endangered animals in this area? revealed a significant result $\left(X^{2}(4)=113.366, p<0.001\right)$, indicating that there is a significant difference between the knowledge about endangered plant and animal species. Sixty-four percent did know that there are endangered plants in the area, but only $26 \%$ knew that there were endangered animals living in the surrounding area. It became clear that more respondents were of the opinion that there were endangered plant species in the study area, compared to animal species. A total of $21.3 \%$ did not know whether there were any endangered plant or animal species in the area and a comparable amount (22\%) knew that there were both endangered animal and plant species. Looking at the knowledge of endemic species, the crosstab revealed a significant result $\left(X^{2}(4)=116.225, p<0.001\right)$ and there was a significant difference between the knowledge of endemic plant and animal species. The results showed that $20(6.7 \%)$ people thought that there are no plant or animal species which only exist in that area, however, 73 (24.3\%) respondents indicated that there are both plant and animal species which are endemic.

Additionally, to the qualitative analysis of knowledge on endangered/endemic species, a third analysis was conducted, using a mentioned number of endangered animal and plant species. The crosstab analysis generated a significant result $\left(X^{2}(12)=30.366, p=0.002\right)$ showing that $107(35.7 \%)$ persons could not name any species, 117 (39\%) respondents knew at least one plant species but no animal species, and $13(4.3 \%)$ respondents did not know any plant species but knew one or more animal species. A total of $63(21 \%)$ people knew at least one plant and one animal species. However, this indicates that the respondents generally knew more plant than animal species (see Table 1).

Table 1. Endangered plant and animal species named by the respondents.

\begin{tabular}{|c|c|c|c|c|c|c|c|}
\hline & & & \multicolumn{5}{|c|}{ Named Endangered Animal Species } \\
\hline & & & $\begin{array}{c}\text { No } \\
\text { Species }\end{array}$ & $\begin{array}{c}\text { One } \\
\text { Species }\end{array}$ & $\begin{array}{c}\text { Two } \\
\text { Species }\end{array}$ & $\begin{array}{l}\text { Three } \\
\text { Species }\end{array}$ & Total \\
\hline \multirow{10}{*}{$\begin{array}{l}\text { Named endangered } \\
\text { plant species }\end{array}$} & \multirow{2}{*}{ No species } & Number & 107 & 10 & 2 & 1 & 120 \\
\hline & & $\%$ of total & $35.7 \%$ & $3.3 \%$ & $0.7 \%$ & $0.3 \%$ & $40.0 \%$ \\
\hline & \multirow[t]{2}{*}{ One species } & Number & 59 & 20 & 5 & 2 & $\begin{array}{c}86 \\
2870\end{array}$ \\
\hline & & $\%$ of total & $19.7 \%$ & $6.7 \%$ & $1.7 \%$ & $0.7 \%$ & $28.7 \%$ \\
\hline & \multirow{2}{*}{ Two species } & Number & 27 & 8 & 3 & 2 & 40 \\
\hline & & $\%$ of total & $9.0 \%$ & $2.7 \%$ & $1.0 \%$ & $0.7 \%$ & $13.3 \%$ \\
\hline & \multirow{2}{*}{ Three species } & Number & 20 & 8 & 4 & 3 & 35 \\
\hline & & $\%$ of total & $6.7 \%$ & $2.7 \%$ & $1.3 \%$ & $1.0 \%$ & $11.7 \%$ \\
\hline & \multirow{2}{*}{$\begin{array}{l}\text { More than } \\
\text { three species }\end{array}$} & Number & 11 & 4 & 3 & 1 & 19 \\
\hline & & $\%$ of total & $3.7 \%$ & $1.3 \%$ & $1.0 \%$ & $0.3 \%$ & $6.3 \%$ \\
\hline \multirow{2}{*}{\multicolumn{2}{|c|}{ Total }} & Number & 224 & 50 & 17 & 9 & 300 \\
\hline & & $\%$ of total & $74.7 \%$ & $16.7 \%$ & $5.7 \%$ & $3.0 \%$ & $100.0 \%$ \\
\hline
\end{tabular}


Another crosstab on the quantitative knowledge of endemic species revealed very similar results (Pearson $\left.X^{2}(12)=23.703, p=0.022\right)$, indicating that one-third (117 out of 300 respondents) did not know any species, while 99 (33\%) people knew at least one plant but no animal species. A total of $26(8.6 \%)$ respondents knew no plant but a minimum of one animal species and $58(19.3 \%)$ respondents knew both one plant and one animal species (Table 2).

Table 2. Plant and animal species that only exist in the Taita Hills Cloud Forest (THCF) named by the respondents.

\begin{tabular}{|c|c|c|c|c|c|c|c|}
\hline & & & \multicolumn{5}{|c|}{ Named Animal Species Which Only Exist Here } \\
\hline & & & $\begin{array}{c}\text { No } \\
\text { Species }\end{array}$ & $\begin{array}{c}\text { One } \\
\text { Species }\end{array}$ & $\begin{array}{c}\text { Two } \\
\text { Species }\end{array}$ & $\begin{array}{l}\text { Three } \\
\text { Species }\end{array}$ & Total \\
\hline \multirow{6}{*}{$\begin{array}{l}\text { Named plant } \\
\text { species which only } \\
\text { exist in the THCF }\end{array}$} & \multirow{2}{*}{ No species } & Number & 117 & 21 & 4 & 1 & 143 \\
\hline & & $\%$ of total & $39.0 \%$ & $7.0 \%$ & $1.3 \%$ & $0.3 \%$ & $47.7 \%$ \\
\hline & One species & $\begin{array}{l}\text { Number } \\
\% \text { of total }\end{array}$ & $\begin{array}{c}63 \\
21.0 \%\end{array}$ & $\begin{array}{c}29 \\
9.7 \%\end{array}$ & $\begin{array}{c}4 \\
1.3 \%\end{array}$ & $\begin{array}{c}3 \\
1.0 \%\end{array}$ & $\begin{array}{c}99 \\
33.0 \%\end{array}$ \\
\hline & Two species & $\begin{array}{l}\text { Number } \\
\% \text { of total }\end{array}$ & $\begin{array}{c}24 \\
8.0 \%\end{array}$ & $\begin{array}{c}10 \\
3.3 \%\end{array}$ & $\begin{array}{c}2 \\
0.7 \%\end{array}$ & $\begin{array}{c}2 \\
0.7 \%\end{array}$ & $\begin{array}{c}38 \\
12.7 \%\end{array}$ \\
\hline & Three species & $\begin{array}{l}\text { Number } \\
\% \text { of total }\end{array}$ & $\begin{array}{c}10 \\
3.3 \%\end{array}$ & $\begin{array}{c}2 \\
0.7 \%\end{array}$ & $\begin{array}{c}2 \\
0.7 \%\end{array}$ & $\begin{array}{c}0 \\
0.0 \%\end{array}$ & $\begin{array}{c}14 \\
4.7 \%\end{array}$ \\
\hline & $\begin{array}{l}\text { More than } \\
\text { three species }\end{array}$ & $\begin{array}{l}\text { Number } \\
\% \text { of total }\end{array}$ & $\begin{array}{c}2 \\
0.7 \%\end{array}$ & $\begin{array}{c}3 \\
1.0 \%\end{array}$ & $\begin{array}{c}1 \\
0.3 \%\end{array}$ & $\begin{array}{c}0 \\
0.0 \%\end{array}$ & $\begin{array}{c}6 \\
2.0 \%\end{array}$ \\
\hline \multirow{2}{*}{\multicolumn{2}{|c|}{ Total }} & Number & 216 & 65 & 13 & 6 & 300 \\
\hline & & $\%$ of total & $72.0 \%$ & $21.7 \%$ & $4.3 \%$ & $2.0 \%$ & $100.0 \%$ \\
\hline
\end{tabular}

The cross tabulations shown above reveal a statistically significant greater knowledge of plant species compared to animal species. One-sided and two-sided non-parametric correlations confirmed that the factor knowledge of species is more strongly influenced by knowledge of plants (mentioned endangered plant species and mentioned plant species which only exist in the THCF), than by knowledge about animals (mentioned endangered animal species and mentioned animal species which only exist in the THCF). The results for the one-sided correlation are as followed:

- Spearman's rho for endangered plants: $r=-0.289, p<0.01$

- Spearman's rho for endemic plants: $r=-0.315, p<0.01$

- Spearman's rho for endangered animals: $r=-0.028, p=0.316$

- Spearman's rho for endemic animals: $r=-0.128, p=0.015$ (significant at the level of 0.05)

The following citations from the expert interviews support the quantitative results. In expert interview I5, the respondents were asked whether and to what extent the local population and institutions are aware of the sensitivity and fragility of the ecosystems in the area and one of them stated: "They [the locals] are aware! They are aware of what is changing. They are well informed. They causing what is happening. They are the ones, who talk about it.". Another interview partner from expert interview I3 also thought that the local population recognized that the environment was changing but also said that they might not know why.

Furthermore, considering hypothesis two, it has been claimed that people in the THCF area have a greater knowledge of plants than of animals. Interview partner I3 said the following: "We like staying with farm animals. But the wild animals, I fear. So surely, we are not free with. So, let them stay in the reserve." The respondent in expert interview I4 precisely addressed this point. Through studies by Nature Kenya (I4), it was found that people had a greater knowledge about plants than animals and, in addition, that they did not treat wild animals very respectfully.

When asked why people are more interested in plant than in animal protection, interviewee I6 commented that this is not true, in fact, they protect the animals as well-especially since a hunting 
ban was issued by CFA and KFS (Kenya Forest Service) because the locals kept using the wildlife as a food supply.

Through expert interviews with I3, I4, and I5, it became clear that those who want to advance the protection of the forest and of the wild forest animals face the situation that the locals want to be compensated for their expenses or that the local people do not understand or see the urgent need to change some behaviors (e.g., I5: "[ ... ] we are the protectors of the animals, we should get a percentage"). This is precisely the decisive issue for an anthropocentric or ecocentric attitude regarding nature conservation.

Human-wildlife conflicts were also identified by the observation protocols, in which they were mentioned several (16) times. Statements like "Monkeys should be killed." (277) were made. In the remaining 200 cases, conflicts with wildlife, mostly with monkeys, were recorded 16 more times. Furthermore, five people said that animals should be protected as a food supply. On the other hand, eight people stated that animals should be protected for future generations, or because they have a right to live (3 times), because they are God's creatures (3 times), or because they are important (8 times). Over a quarter of the 200 endorsed animal welfare so that tourists come to the area (51 times). This could also be seen in the 100 observation protocols. Thirty-five people want animals to be protected as tourism attractions. During observation, the intrinsic value of wild animals was expressed in 20 cases and statements such as the following were made: “They have their own value!" (234), and: "They [the animals] have a right to live" (255).

To explore what the people think about plant and animal protection around the THCF, the hypothesis "Better situated respondents with greater land size are more willing to protect plants and animals around the THCF" was analyzed using a univariate three-factor ANOVA in which the term better situated is shown by the variables income per month, level of education, and size of used land. The last item was recoded into an ordinal scaled item and, thus, analyzed in respect of the factor willingness to contribute.

Only the variable income per month $(p=0.001)$ was significant. Thus, a Bonferroni post-hoc test was carried out as a multiple comparison test and showed significant differences regarding the mean between the following groups (in Kenyan shilling (KSh)) (in both directions with the respective sign):

- $\quad<5000 \leftrightarrow 10,001$ to $15,000(+/-1.04,95 \%-C I[+/-1.70,+/-0.38], p<0.001)$

- $\quad<5000 \leftrightarrow>20,000(+/-1.31,95 \%-\mathrm{CI}[+/-2.08,+/-0.54], p<0.001)$

- 5001 to $10,000 \leftrightarrow>20,000(+/-0.96,95 \%-\mathrm{CI}[+/-1.75,+/-0.16], p=0.009)$

In addition, six crosstabs using two questions, summarized from the question In your opinion should plants and animals in THCF be protected? were tabulated with the three variables mentioned before. Only the cross tabulation Should animals be protected? * level of education showed a highly significant result $\left(X^{2}(12)=59.267, p<0.001\right)$. It appears that the level of education had a large effect on how the question of whether animals should be protected was answered. For the cross tabulation with the variable size of used land only the factor Should plants be protected? created a significant result $\left(X^{2}(14)=26.712, p=0.021\right)$. A univariate ANOVA was calculated for the nominal scaled variable Should animals be protected? and the ordinal scaled variable level of education (Welch's $F(6,82.123)=2.345$, $p=0.039$ ). This means that a significant difference in this variable's variance could be determined. The Games-Howell post-hoc test identified two groups that differed significantly from each other (in both directions with the respective sign):

- $\quad$ primary complete $\leftrightarrow$ tertial $(+/-0.366,95 \%-\mathrm{CI}[+/-0.05,+/-0.68], p=0.014)$ (significant)

The measures of effect sizes were small $\left(\eta^{2}=0.040, \omega^{2}=0.021, \varepsilon^{2}=0.021\right)$.

Through the different analyses, it could be confirmed that the level of education influenced the item Should animals be protected?. Furthermore, there was a difference between the two educational groups tertial and primary complete.

Those who were already engaged in CFAs support nature conservation and, when asked, state that they do so to protect both plants and animals. This also emerged from the expert interviews. 
The respondent in interview I1 went further than the existing connection between flora and fauna. Interviewee $\mathrm{I} 2$ also mentioned both plants and animals. In interview I6, the respondent explained that they also protected the animals of the forest and added that when the forest was in better shape, the ecosystem services had a higher output. That is why they were trying to spread knowledge and awareness during their local village meetings, called "barazas".

Since I4 stated that Nature Kenya's mission is to connect people with nature, the establishment in Wundanyi seeks to involve and convince as many people as possible. Therefore, they offer workshops and assistance with establishing alternative livelihood activities and forest conservation groups. In addition, they actively seek to satisfy the needs for livelihoods, knowing that nature conservation cannot function unless the local peoples' needs are met. Therefore, this aspect is incorporated into their projects.

\subsection{What Factors Might Influence an Ecocentric or Anthropocentric Mindset?}

To identify the factors which influence the individual, ethical mindset, the hypothesis "There is a higher percentage of anthropocentric reasoning people than ecocentric ones" was stated. Of the 100 cases for which both observations and interviews were available, it was found that 71 people had an anthropocentric perspective and 23 an ecocentric one, in terms of protecting biodiversity. However, six cases could not be clearly assigned and were investigated repeatedly, as described above. These six cases which could not be assigned to either anthropocentrism or ecocentrism have been summarized as a hybrid form.

The answers to these questions had great potential for providing an understanding of the motivations and background leading to respondents taking an anthropocentric or ecocentric approach to the protection of plants and animals. It was possible to identify a differentiated understanding of the protection of flora and fauna. In statistical terms, the respondent (230) would be assigned to anthropocentrism. However, the recognition of self-responsibility to protect the forest was manifested in the answers. Even basic features of animal protection were identifiable, apart from monkeys, since their destructive behavior threatened the respondent's existence. A distinction between monkeys and other animals was made and, therefore, the answers, especially in the open question section, were very precise and attributed to human-wildlife conflicts. These cases have ensured that the data were processed with greater care and sensitivity.

Anthropocentrism was attributed to those who clearly opposed the protection of flora and/or fauna, did not acknowledge their own responsibility for the protection of the forest, or stated that neither the indigenous knowledge nor the forest itself were of personal importance to them. When assigning whether a respondent or an observed person was anthropocentric or ecocentric, not only the closed questions from the questionnaire were considered in the evaluation. Much more consideration was given to the statements that people made on open questions, along with observations. Therefore, what was important was their motives, why they gave this answer or, respectively, why they had such an attitude. In addition, the respondents who agreed to the protection of flora and fauna but who endorsed it purely for self-seeking reasons were also considered anthropocentric. Statements were classified as egotistical if they advocated the protection of the forest to preserve firewood or agreed to protect the animals so that tourists would come to the area. For example, respondent (7) agreed that animals should be protected but the explanation was: "We get meat". Another example was that respondent (277) denied that animals should be protected and added: "They destroy our crops, monkeys should be killed". Respondent (278) was against protection for plants as well as for animals. She stated that plants should not be protected, as, "[i]f the government wishes to protect the forest it is alright, if they do not protect, it is also alright, we will go in and get firewood" while animals did not need to be protected because "[i]f someone wishes to eat the wild animals, they eat". These quotes were assigned to an anthropocentric attitude. If a person had an ecocentric mindset, the interpretation was done similarly.

Several attempts were made to assign the respondentss to one or the other centrism, but this could not be done without losing stringency. Following the observed phenomenon of differentiated 
protection of flora and fauna, it could be determined that the six cases identified were based on a common ground that prevented the participants from adopting a purely ecocentric perspective. However, their explanatory statements were also not anthropocentric. They showed high awareness and a sense of responsibility. The existence of human-wildlife and/or government conflict(s) influenced participants to take a hybrid perspective. The government and the conflicts associated with it were recorded in 18 of the observation protocols completed for 100 interviews with the local population. In addition, in five of the standardized interviews, it was explicitly stated that those surveyed felt politically dependent. The observation records revealed displeasure with the government in 18 cases and human-wildlife conflicts with the monkeys living there were mentioned 16 times.

Another reason for less participation and/or willingness to contribute can be seen in a deficit sense of responsibility. Since these can be understood as being partly responsible for an anthropocentric or ecocentric mindset, some quotations are presented here:

Interview partner I3 explained the conflict between the local population around the Taitas and wildlife in detail. He stated that over $60 \%$ of Taita's land or "of our land is now for wild animals.". The national parks receive revenue from the tourists who come for the wildlife; the locals want a percentage. Once more, these conflicts, circumstances, and associated impressions of the local people play a tremendous role in whether a person has an anthropocentric or ecocentric attitude. Respondent I4 was very clear on this topic and addressed the problem between wildlife and humankind, specifically to the latter: "The greatest contributor towards human-wildlife conflict are the humans themselves [ ... ]". According to him, the people were responsible for the conflicts themselves as they had left the animals no choice but to defend themselves. People spread without regard to traditional waterholes and animal migration paths. In addition, he said "[ ... ] we have found through our research people [ ... ] do not have a very ecocentric attitude towards the animals [... ]". Human-wildlife conflicts are a component of human-environment or human-nature relationships and, in this case, also part of the conflict of interests, as well as the human-government conflicts.

Respondents from 15 also recognized conflicts between farmers and the forest and were anxious to regulate them (I5, line 154). Furthermore, they reported heterogeneous interest conflicts between the government and local people, especially when it comes to harvesting their trees. At this point, the CFA wants to play a mediating role (I5, lines 238-245).

In order not to neglect unidentified influences from the outset, the nominally scaled variable centrisms, was tested in a multivariate general linear model with all eight factors formed in the second factor analysis. The model revealed significance for the factor appreciation and perception of nature $(p=0.040)$. The tests for the inter-subject effects were not significant for any combination, except for appreciation and perception of nature $(\mathrm{F}(2,0.95)=3.334, p=0.040$, corrected $R$-Square $=0.50)$ and, thus, the model explains $50 \%$ of the variance.

Building on this finding, Welch ANOVA was applied $(\mathrm{F}(2,13.388)=4.026, p=0.043)$, showing that a significant difference does exist. The Games-Howell post-hoc test was used to identify its location between groups, and the following significant differences were found (in both directions with the respective sign):

- Anthropocentrism $\leftrightarrow$ Ecocentrism $(+/-0.586,95 \%-\mathrm{CI}[+/-1.09,+/-0.08], p=0.020)$

This shows that the anthropocentric or ecocentric reasoning had an influence on the factor appreciation and perception of nature. The commitment to nature increased when someone had an ecocentric mindset. In addition, cross tabulations were performed to test other singular variables instead of factors and the variable gender had a significant influence on whether an anthropocentric or ecocentric perspective was adopted $\left(X^{2}(2)=9.321, p=0.009\right)$. A multi-layered cross tabulation with the nominal scaled variables gender and centrisms and the additional item Should animals be protected? was performed to combine more than two aspects of interest $\left(X^{2}(4)=17.648, p=0.001\right)$. The results of the multi-layered crosstab showed that $27.5 \%$ of women are anthropocentric and answered the question of animal protection in the negative. However, this combination applied to only $12.2 \%$ of male 
respondents. In contrast, $32.7 \%$ of ecocentric men answered yes to the question, which was true for just $13.7 \%$ of the female respondents (Table 3).

Table 3. Multi-layered cross tabulation with three items.

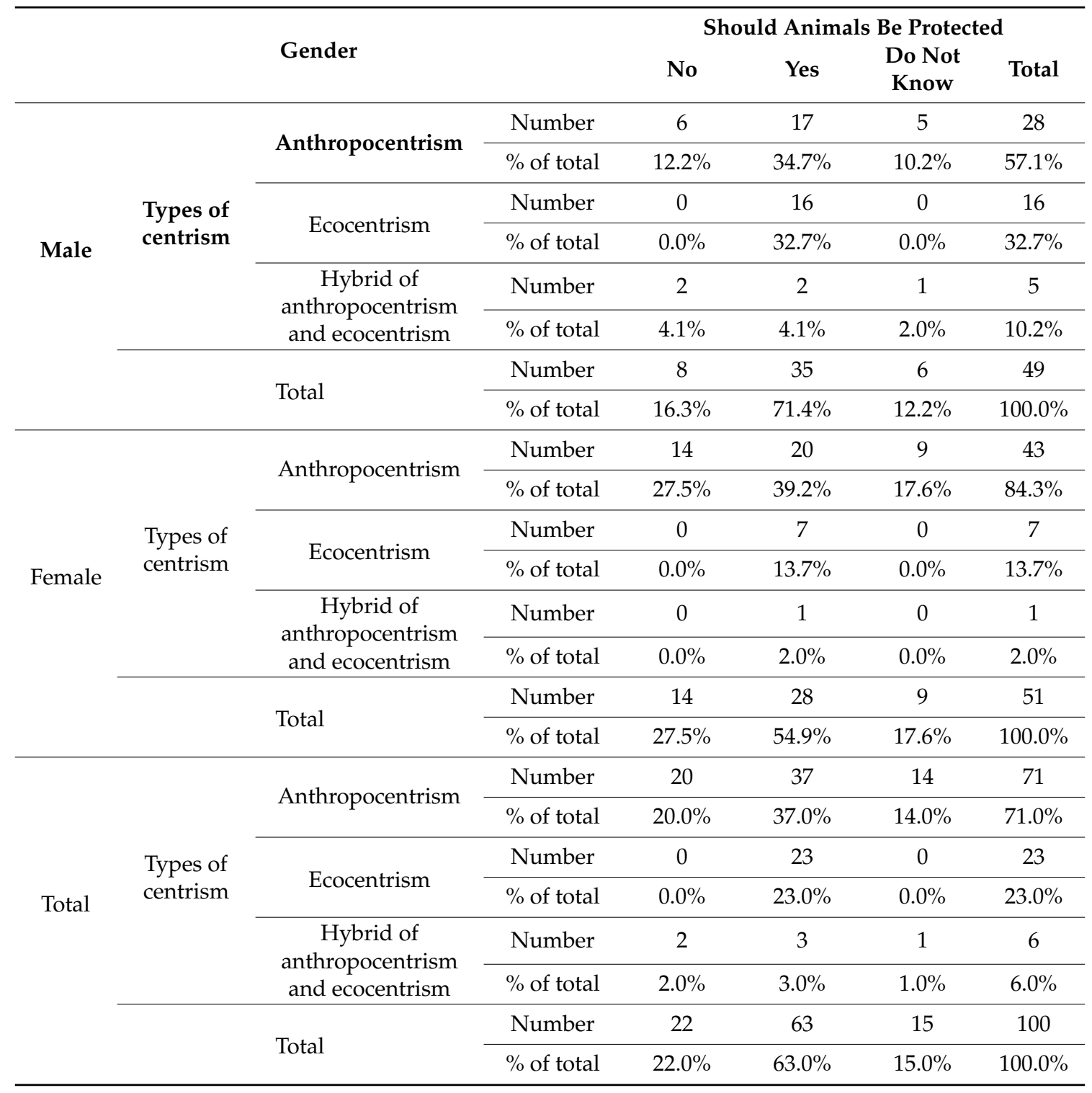

\section{Discussion}

Our study within the 300 respondents located in the THCF revealed that a greater knowledge about plants than animals does exist, even though some of the respondents were aware of the high endemic biodiversity. In addition, gender has been shown to influence opinions on whether or not animal welfare is promoted. This confirms the findings of Dubois and Fraser, Zinn and Pierce, and Davidson and Freudenberg [76-78]. However, in contradiction to our findings, Zinn and Pierce revealed that women rate environmental risks higher, though, e.g., mountain lions, but they promote nature conservation and animal welfare more than men do [77]. Experienced conflicts (human-wildlife and government conflicts) had an impact on the assignment of a person to the respective centrism. The abovementioned results reveal that different influences control whether a person adopts an anthropocentric or ecocentric attitude and that a simple assignment cannot be done.

We found that 71 of the 100 observed respondents had an anthropocentric attitude towards nature and its conservation, while 23 respondents had an ecocentric perspective on the topic. There was no 
easy way to attribute people's expressions and statements to certain types of centrism and attitudes. Therefore, there were six respondents $(9,230,250,256,169,97)$ who could not be clearly assigned to either of these types of centrism. However, it can be stated that just as individual people are very different, so are their specific reasons and motivations for embracing a certain attitude. Hence, there must be an equally differentiated form to which their attitude can be assigned. Thus, in Figure 2, pathocentrism, which involves all living beings capable of suffering, has been replaced by ecanthrocentrism. During the analysis, we called ecanthrocentrism a "hybrid of anthropocentrism and ecocentrism", since it actually is a hybrid form between these two types of centrism. In principle, recognizing nature, its intrinsic value, and worthiness of protection, as well as the recognition of its destruction, are clear criteria for belonging to ecocentrism. To act against these recognitions, however, is contradictory and speaks in favor of belonging to anthropocentrism. However, the two affiliations are mutually exclusive. This complexity as well as the consideration of the existing appreciation and the simultaneous lack of action make a special possibility of assignment reasonable. It is similar to Hoffman and Sandelands's study about different types of centrism in a religious context [79]. They identified a centrism between anthropocentrism and ecocentrism and applied this to theology. Their theocentrism is defined as follows: "To distance nature from ourselves, by treating it as object to our subject or by seeing it as inanimate and subservient to our material desires, is to falsify its truth, which is that it is, as we are, a creation of God." [79] (p. 159). In our study, one ecocentric respondent's (10/10) answer to the question "Why should animals be protected?" was, "God's creation", which was her reason for wanting them to be protected. Furthermore, one anthropocentric person (249/51), another ecocentric person (238/40), and one belonging to ecanthrocentrism, mentioned God in other contexts. Seven more of the 200 respondents who were not observed also mentioned God in different contexts. Four of them $(36,101$, $120,125)$ named God as the reason why animals should be protected. However, a religious reason cannot be assumed to be the only reason for adopting a specific mindset since others did not mention religion as being their reason. Christianity was the declared religion in 296 cases and 204 respondents stated that their religion taught them about indigenous knowledge.

The respondents who belonged to ecanthrocentrism were able to communicate their specific backgrounds and reasons for agreeing or disagreeing with certain aspects.

Conflicts were the common denominator by which we identified them as a group. They named these conflicts and explicitly identified the source of conflicts that were tangible to them. In this case, there were conflicts with monkeys, which are assigned to human-wildlife conflicts. Since monkeys are higher mammals and capable of suffering, they should be considered in pathocentrism [5]. However, they are not considered by this group. For some people, monkeys do not count because they threaten the people's existence by destroying their harvests. Due to the very specific neglect of great apes in the present research, apart from a general commitment to nature and its conservation, the term ecanthrocentrism is introduced. In the present example, all possible animals are neither included nor excluded. It is a directed exclusion of a specific species. At the same time, the people assigned to this hybrid form support the conservation of nature, and have a kind of reflective relationship to this topic.

Our findings are in accordance with Hockings et al. and McLennan, as they discovered that interactions between human beings and wildlife, more specifically monkeys, increased in "anthropogenic habitats" [80] (p. 299), or "anthropogenic landscapes" [81] (p. 269). Where people and wild animals have to coexist side by side, the conflicts become perceptible for both parties, which could also be seen in this study. This accords with one respondent from I3, who stated that he was afraid and, therefore, not free with wild animals (I3, lines 291-292). Kaltenborn et al. argued that the fear of wildlife increases with age [82]. This finding correlates with I3's statement. Personal experiences of human-wildlife issues have more influence in terms of willingness for personal commitment than taught and globally accepted attitudes towards nature conservation, especially considering animal welfare [82]. 


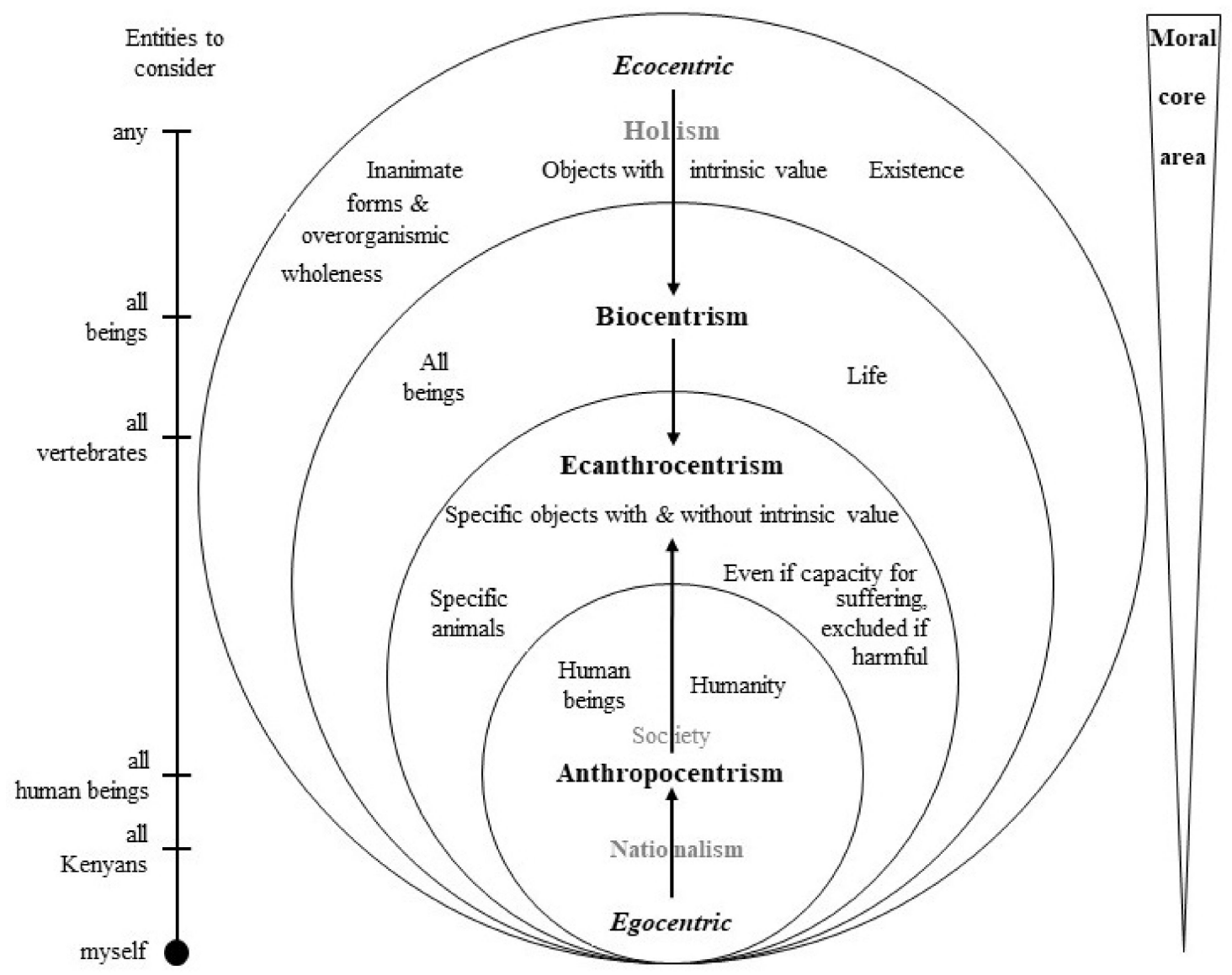

Figure 2. Adjusted types of centrism (own illustration based on reference [5]).

This can be connected to the factor "knowledge of species", amongst others, for both data sets (entire and 100 cases), since those who have a higher education advocate for animal welfare more, in contrast to those with a lower educational level. Generally, a higher level of education had a positive effect on the factors "appreciation and perception of nature", "personal engagement for nature", and "willingness to contribute" and the question "Should animals be protected?" but had no influence on the item centrisms. Conversely, this also means that a lower level of education had a negative effect on the factors mentioned. For the question "Should animals be protected?" and by considering the combination of the items centrisms and gender, it emerged that a higher percentage was female, anthropocentric, and answered this question in the negative (Table 3). In addition, an influence on the factor appreciation and perception of nature could be identified for two age groups. A significant difference was found between the 29 to 39 and $62+$ groups. This may occur due to the older people's resignation or indifference and an increased sense of responsibility within the 29 to 39 cohort. The latter are in the position of educating their own children and are engaged with managing their properties and sustainably safeguarding their future. These might be reasons why the younger cohort has a higher appreciation and perception of nature [83].

As the results revealed that education had a significant influence on various aspects and that negative effects were observed at a lower level of education; this is an important component that should be considered in future in the context of sustainable development and nature conservation. As Rieckmann and Sterling postulated, sustainable education is indispensable for sustainable development $[84,85]$. This could also be seen in the results of the surveys conducted. Out of 300 respondents, 85 people mentioned future generations at various points during the questionnaire-for example, in the context of why it is important to teach children about indigenous knowledge or why animals and plants should be protected. Furthermore, more than $80 \%$ of the respondents stated they have an individual responsibility for the protection of the forest. Moreover, $51.2 \%$ said that the local people themselves 
should be in charge of protecting the forest and $40.2 \%$ stated that this should be a governmental duty. These results should be used as guidance for future conservation measures in the THCF and probably could be promoted by monetary incentives to sustain the environment for future generations. Although, more locality-specific research is needed on the aspect of possible incentives.

In addition, interviewee I4 explained that the population believes that the monkeys belong to the government and, thus, are its problem. They expect the government to take care of the matter, however, as long as it does not, the conflicts will increase as well as resignation and disappointment in the government will grow (I4, lines 419-424). This, in turn, agrees with a statement from expert interview I5, in which the respondents stated that they want to be compensated for protecting the animals, since they are the true protectors of the animals (I5, lines 314-316).

Human-wildlife conflicts are a component of human-environment or human-nature relationships and, in this case, are also part of the conflict of interests and of human-government conflicts. In addition, they play a crucial role from an ethical point of view since it concerns the preservation and protection of living entities. It is, therefore, important to find a basis for communication and transparency, so that human beings do not feel disadvantaged or even penalized by the protection of animal life [86]. Although human-animal conflicts arise between the local population and the wildlife living in these areas, these conflicts often have another addressee: the government. Thus, the initial conflicts with the animals quickly turn into human-government conflicts, as respondent I3 (lines 293-303) reports: "[ ... ] in Taita, $62 \%$ of our land is now for animals, wild animals. Sixty-two percent of Taita land is national park. [... ] And now, they are starting to protect the animals." The disappointment or fear of losing one's basis of existence, the feeling of being neglected or of being unfairly treated by politicians, often results in negativity, indifference, and a reduced sense of responsibility among the population. Here, two different conflicts could be identified as the cause: human-wildlife conflicts and human-government conflicts. Human-wildlife conflicts were mentioned 16 times during the observations, while the government was identified as the cause of conflicts 18 times. Furthermore, a political dependency or the feeling of being politically suspended were emphasized five times.

Conflicts with wildlife were not the only problem attributed to the government identified in this study. As the respondents from I5 recognized farmer-forest conflicts, they reported heterogeneous conflicts of interest between the government and the local people, especially when it comes to harvesting trees. They are facing a lot of bureaucracy in terms of required permits to be allowed to log on their own land (I5, lines 238-245). The fact that trees could no longer be felled without informing the government was something that these interview partners considered very reasonable and necessary. The population is not allowed to harvest indigenous tree species because of rehabilitating and reforesting this specific area [87]. The aim is to create corridors that certain fauna can use for migration to persist. The project by Newmark in the East Usambara Mountains in Tanzania can be given as an example of best practice [88]. Furthermore, some exotic tree species have invasive characteristics which means they occupy a whole ecosystem if they start to spread [21,26]. In terms of profit, exotic tree species, like eucalyptus, are very efficient because they grow faster in a shorter period of time (I5, lines 253-257). The government establishes laws and enforces them for a good reason. It wants to reforest the area to regenerate the forest and the ecosystems as well as to connect fragments [87]. To return these forests around the Taita Hills to their original form or even something close to it, those responsible must consider the many different aspects of these complex ecosystems. To bring back indigenous tree species and reduce exotic ones would bring back more biodiversity in the form of vegetation and animal (invertebrates and vertebrates) diversity $[23,26,88,89]$. However, it does not appear to take the everyday needs of the rural population in situ into consideration, as reported by I4 (lines 390-392). They are supposed to plant indigenous trees, but they are not allowed to harvest them. Exotic species are allowed to be felled and they also grow faster. This conflict between the goal, the implementation, and the applicability of what is designed to protect the forest, ultimately, drives people to continue planting exotic species rather than indigenous ones, especially considering that most participants often have a limited area for use. 
Personal engagement with nature is an important factor in conservation. When the absence of results leads to disappointment or resignation, people cease to get involved. This is also mentioned by Hohenthal et al., as well as by Mbuvi et al. [90,91]. The interview partners in I5 (lines 33-40) reported how the locals were disappointed because government officials had reportedly contributed to the logging of the natural forest of Taita Hills but had not shared the accrued benefits with those who had protected the forest for so long. According to them, local people's harmful behavior which caused the loss of biodiversity was not due to their deficient knowledge rather than their resignation and disappointment towards the government (I5, lines 12-15, 33-47, 259-263). This shows how drastically the situation can turn into the exact opposite and that appreciation and perception for nature can turn into indifference, even disappointment, anger, and related malicious behavior. Here, human-government conflicts can be identified again.

Since the Taita Hills have already lost approximately $99 \%$ of their former original forest, there is no more time to waste in establishing sustainable solutions in order to secure human livelihoods and protect the remaining nature [23]. Vandermeer et al., like Jaetzold, believe that local farmers know a lot about their land and have ancient valuable indigenous knowledge $[57,92]$. However, this should be combined with modern agricultural techniques for small-scale farming. On the one hand, this can make the yields safer for the farmers and their families, whereby this, of course, is also significantly influenced by abiotic factors [93]. Secondly, the farm management could be adapted to the specific ecosystem, combining subsistence farming and nature conservation in a realistic way [94]. This is even more important in the context of $240(80 \%)$ people's statements that they earn at least part of their income from farming; $213(71 \%)$ declared it as their main source of income.

Further research should include more aspects to cover patterns of behavior such as collecting firewood from the forest, hunting wild animals, or setting bush fires to differentiate between the verbalized statements and the actual day-to-day actions and, generally, to obtain a more accurate picture of the factors humankind and nature are facing.

Supplementary Materials: The following are available online at http://www.mdpi.com/2071-1050/12/19/8213/s1, Table S1: Interviewees responses, S2: Questionnaire, rotated Component Matrix of factor analyses and transcript of expert interviews.

Author Contributions: During creation of this manuscript the following contributions were made by the authors. Conceptualization, J.R. and M.T.; methodology, J.R.; software, J.R.; validation, M.R.; formal analysis, J.R.; investigation, J.R. and J.M.N.; resources, J.R.; data curation, M.T.; writing-original draft preparation, J.R.; writing-review and editing, J.R., M.R., J.M.N., and M.T.; visualization, J.R.; supervision, M.R.; project administration, M.T. and M.R.; funding acquisition, M.T. All authors have read and agreed to the published version of the manuscript.

Funding: This research was funded by the German Academic Exchange Service. We acknowledge the financial support within the funding programme Open Access Publishing by the German Research Foundation (DFG).

Acknowledgments: We thank the German Academic Exchange Service for funding the DAAD Quality Network Biodiversity Kenya. We thank Ruth Lozi Muranga, Timothy Musa, Slas Neguse, Anna Nies, Althea Hochtritt, and Tobias Bendzko for their valuable support during our field work. We thank to Karl Martin Born for his valuable support during writing, reviewing and editing of this manuscript. We thank the anonymous reviewers for critical and helpful comments on a draft version of this article.

Conflicts of Interest: The authors declare no conflict of interest. The funders had no role in the design of the study; in the collection, analyses, or interpretation of data; in the writing of the manuscript; or in the decision to publish the results. 


\section{Appendix A}

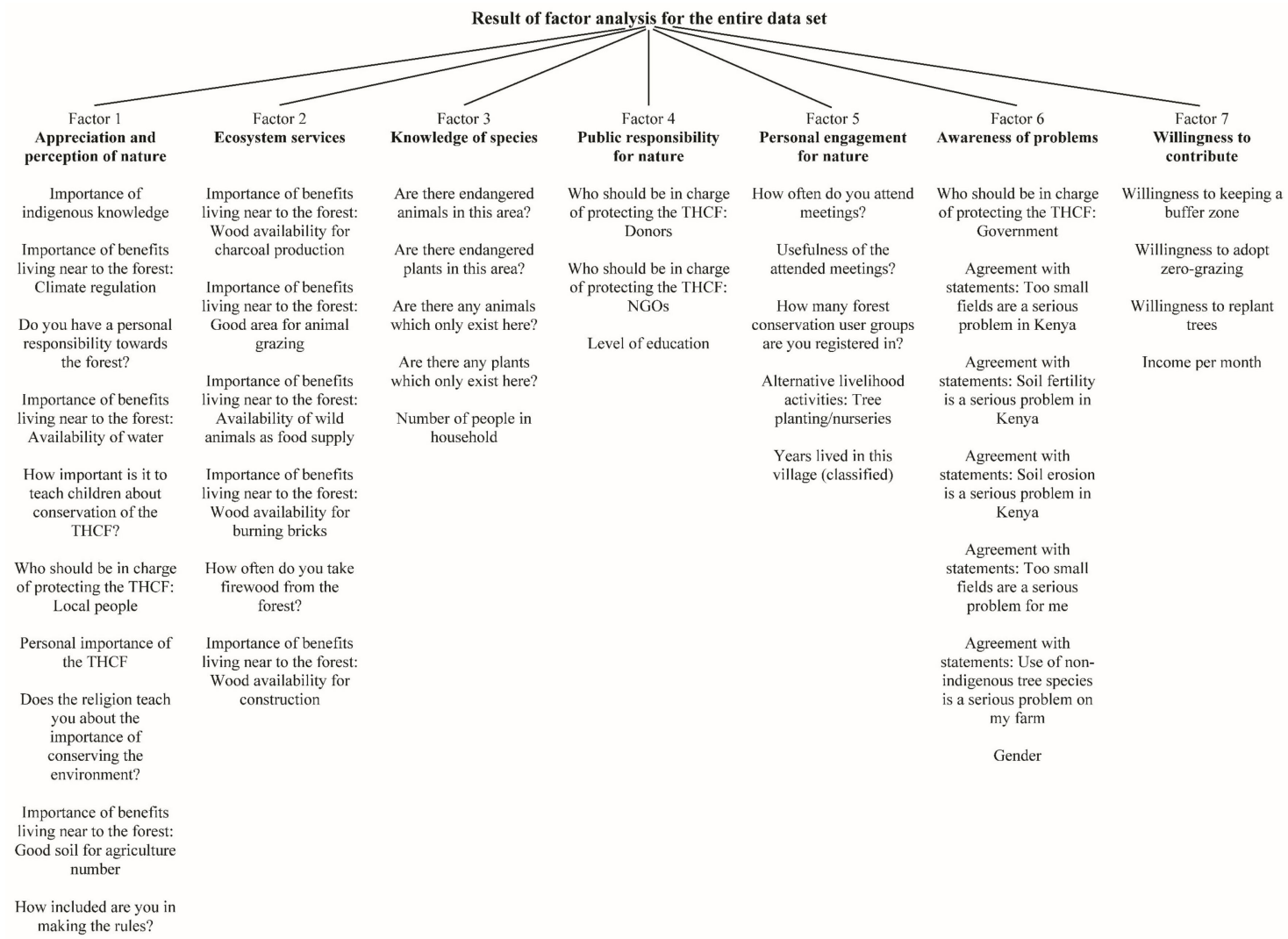

Figure A1. Grouping of variables to factors for entire data set using cluster analysis.

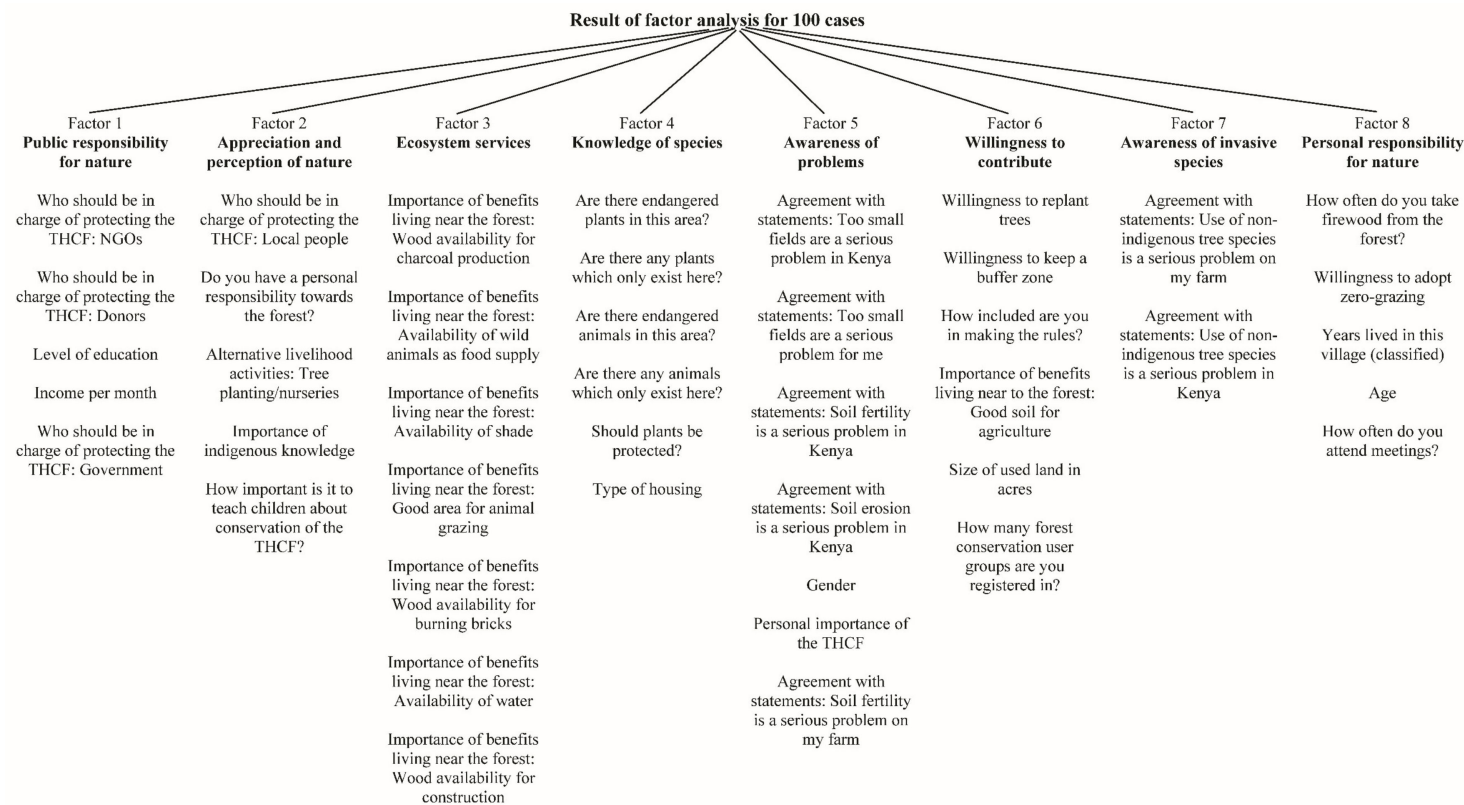

Figure A2. Grouping of variables to factors for sub-selected 100 cases data set using cluster analysis.

\section{References}

1. Lévêque, C.; Mounolou, J.-C. Biodiversity; Wiley: Chichester, UK, 2003.

2. Woods, M. Rural Geography: Processes, Responses and Experiences in Rural Restructuring; SAGE Publications: Los Angeles, CA, USA, 2011. 
3. Whaley, L. Geographies of the Self: Space, Place, and Scale Revisited. Hum. Arenas 2018, 1, 21-36. [CrossRef]

4. Daniels, P.W.; Bradshaw, M.J.; Shaw, D.J.B.; Sidaway, J.D.; Hall, T. An Introduction to Human Geography, 5th ed.; Pearson: Harlow, UK, 2016.

5. Gorke, M. The Death of Our Planet's Species: A Challenge to Ecology and Ethics; Island Press: Washington, DC, USA; Covelo, CA, USA; London, UK, 2003.

6. Ott, K. Environmental Ethics. In Online Encyclopedia Philosophy of Nature, 2019/Online Encyclopedia Philosophy of Nature; Kirchhoff, T., Ed.; OEPN: Heidelberg, Germany, 2020. [CrossRef]

7. Holmes, R.L. Introduction to Applied Ethics; Bloomsbury Academic: London, UK, 2018.

8. Taylor, B.R. Environmental Ethics. In Encyclopedia of Religion and Nature; Taylor, B.R., Ed.; Continuum: London, UK, 2005; pp. 597-608.

9. Eser, U. Inklusiv denken: Eine Kritik der Entgegensetzung von Humanität und Natur. In Die Welt im Anthropozän. Erkundungen im Spannungsfeld zwischen Ökologie und Humanität; Haber, W., Held, M., Vogt, M., Eds.; Oekom: Munchen, Germany, 2016; pp. 81-92.

10. Rorty, R.; Williams, M. Philosophy and the Mirror of Nature; Princeton University Press: Princeton, NJ, USA; Oxford, UK, 2009.

11. Meyer, M.W. Reverence for Life: The Ethics of Albert Schweitzer for the Twenty-First Century, 1st ed.; Bergel, K., Ed.; Syracuse University Press: Syracuse, NY, USA, 2002.

12. Charmaz, K.; Thornberg, R.; Keane, E. Evolving Grounded Theory and Social Justice Inquiry. In The SAGE Handbook of Qualitative Research, 5th ed.; Denzin, N.K., Lincoln, Y.S., Eds.; SAGE: Los Angeles, CA, USA, 2018; pp. 411-443. ISBN 9781483349800.

13. Strübing, J. Grounded Theory und Theoretical Sampling; Springer VS: Wiesbaden, Germany, 2014; pp. 457-472.

14. Steiner, C. Von Interaktion zu Transaktion -Konsequenzen Eines Pragmatischen Mensch-UmweltVerständnisses für eine Geographie der Mitwelt. Geogr. Helv. 2014, 69, 171-181. [CrossRef]

15. Steiner, C. Pragmatismus-Umwelt-Raum. Potenziale des Pragmatismus für eine Transdisziplinäre Geographie der Mitwelt; Franz Steiner Verlag: Stuttgart, Germany, 2014.

16. Brandt, M. Von der Umwelt Zur Mitwelt. Zur Fundierung Eines Neuen Pädagogischen Paradigmas Auf der Basis der Philosophie John Deweys; Peter Lang: Frankfurt am Main, Germany, 2000.

17. Becker, C.U. Sustainability Ethics and Sustainability Research; Springer: Dordrecht, The Netherlands, 2012.

18. Kenya National Bureau of Statistics (KNBS); Society for International Development (SID). Exploring Kenya's Inequality: Taita Taveta County; Kenya National Bureau of Statistics: Nairobi, Kenya; Society for International Development: Nairobi, Kenya, 2013.

19. Capitani, C.; Garedew, W.; Mitiku, A.; Berecha, G.; Hailu, B.T.; Heiskanen, J.; Hurskainen, P.; Platts, P.J.; Siljander, M.; Pinard, F; et al. Views From Two Mountains: Exploring Climate Change Impacts on Traditional Farming Communities of Eastern Africa Highlands Through Participatory Scenarios. Sustain. Sci. 2018, 14, 191-203. [CrossRef]

20. Teucher, M.; Schmitt, C.B.; Wiese, A.; Apfelbeck, B.; Maghenda, M.; Pellikka, P.; Lens, L.; Habel, J.C. Behind the Fog: Forest Degradation Despite Logging Bans in an East African Cloud Forest. Glob. Ecol. Conserv. 2020, 22, e01024. [CrossRef]

21. Brooks, T.; Lens, L.; Barnes, J.; Barnes, R.; Kihuria, J.K.; Wilder, C. The Conservation Status of the Forest Birds of the Taita Hills, Kenya. Bird Conserv. Int. 1998, 8, 119-139. [CrossRef]

22. Lehouck, V.; Spanhove, T.; Vangestel, C.; Cordeiro, N.J.; Lens, L. Does Landscape Structure Affect Resource Tracking by Avian Frugivores in a Fragmented Afrotropical Forest? Ecography 2009, 32, 789-799. [CrossRef]

23. Pellikka, P.K.; Clark, B.J.; Gosa, A.G.; Himberg, N.; Hurskainen, P.; Maeda, E.E.; Mwang'Ombe, J.; Omoro, L.M.; Siljander, M.; Gonsamo, A. Agricultural Expansion and Its Consequences in the Taita Hills, Kenya. In Developments in Earth Surface Processes; Elsevier: Amsterdam, The Netherlands, 2013; Volume 16, pp. 165-179.

24. Boitt, M.K.; Mundia, C.N.; Pellikka, P.K. Land Suitability Assessment for Effective Crop Production: A Case Study of Taita Hills, Kenya. J. Agric. Inform. 2015, 6, 23-31. [CrossRef]

25. Himberg, N.; Omoro, L.M.A.; Pellikka, P.K.E.; Luukkanen, O. The Benefits and Constraints of Participation in Forest Management: The case of Taita Hills, Kenya. FENNIA 2009, 187, 61-76.

26. Pellikka, P.K.; Lötjönen, M.; Siljander, M.; Lens, L. Airborne Remote Sensing of Spatiotemporal Change (1955-2004) in Indigenous and Exotic Forest Cover in the Taita Hills, Kenya. Int. J. Appl. Earth Obs. Geoinf. 2009, 11, 221-232. [CrossRef] 
27. Müller, F. Eco Targets, Goal Functions, and Orientors; Leupelt, M., Ed.; Springer: Berlin/Heidelberg, Germany; New York, NY, USA, 1998.

28. Steiner, C. Mensch-Umwelt-Systeme in der Geographie: Zur Metatheoretischen Möglichkeit Einer Grundlegenden Systemkompetenz. In Mensch: Umwelt: System: Theoretische Grundlagen und praktische Beispiele für den Geographieunterricht; Gryl, I., Schlottmann, A., Kanwischer, D., Eds.; Lit Verlag: Munster, Germany, 2015; pp. 23-42. ISBN 9783643131256.

29. Falter, R.; Hasse, J. Geographie und das Mensch-Natur-Verhältnis. Erdkunde 2002, 56, 81-94. [CrossRef]

30. Wolch, J.; Brownlow, A.; Lassiter, U. Construction the Animal Worlds of Inner-City Los Angeles. In Animal Spaces, Beastly Places: New Geographies of Human-Animal Relations, 1st ed.; Philo, C., Wilbert, C., Eds.; Taylor and Francis: Florence, Italy, 2005; pp. 73-98. ISBN 0203004884.

31. Leser, H. Diercke Wörterbuch Geographie. Raum-Wirtschaft und Gesellschaft-Umwelt; 15, völlig überarb. Aufl.; Westermann: Braunschweig, Germany, 2011.

32. Ratter, B.M.W. Komplexitätstheorie und Geographie: Ein Beitrag zur Begründung Einer Anderen Sicht auf Systeme. Mitt. Osterr. Geogr. Ges. 2006, 148, 109-124.

33. Roe, E. Environmental Ethics. In International Encyclopedia of Geography: People, the Earth, Environment and Technology; Richardson, D., Castree, N., Goodchild, M.F., Kobayashi, A., Liu, W., Marston, R.A., Eds.; John Wiley \& Sons: Hoboken, NJ, USA, 2015; ISBN 9781118786352.

34. Weichhart, P. Gesellschaftlicher Metabolismus und Action Settings.: Die Verknüpfung von Sach—und Sozialstrukturen im Alltagsweltlichen Handeln 44. In Humanökologie: Ansätze zur Überwindung der Natur-Kultur-Dichotomie; Meusburger, P., Schwan, T., Eds.; Steiner: Stuttgart, Germany, 2003; p. 15. ISBN 9783515083775.

35. Egner, H.; Von Elverfeldt, K. A Bridge Over Troubled Waters? Systems Theory and Dialogue in Geography. Area 2009, 41, 319-328. [CrossRef]

36. Luhmann, N.; Bednarz, J. Ecological Communication; Polity Press: Cambridge, UK, 1989.

37. Mattissek, A.; Sakdapolrak, P. Gesellschaft und Umwelt; Springer Science and Business Media LLC.: Berlin/Heidelberg, Germany, 2016; pp. 13-38.

38. Luhmann, N.; Holmes, S.; Larmore, C. Differentiation of Society; Columbia University Press: New York, NY, USA, 1982.

39. Popper, K.R. Objective Knowledge: An Evolutionary Approach; Revised Edition; Clarendon Press: Oxford, UK, 1995.

40. Eusterschulte, A.; Ingensiep, H.W. Philosophie der Natürlichen Mitwelt: Grundlagen, Probleme, Perspektiven: Festschrift für Klaus Michael Meyer-Abich; Meyer-Abich, K.M., Ed.; Königshausen \& Neumann: Würzburg, Germany, 2002.

41. Gryl, I.; Schlottmann, A. Mensch:Umwelt:System. Theoretische Grundlagen und Praktische Beispiele für den Geographieunterricht; Kanwischer, D., Ed.; Lit Verlag: Munster, Germany, 2015.

42. Meusburger, P. Humanökologie. Ansätze zur Überwindung der Natur-Kultur-Dichotomie; Schwan, T., Ed.; Steiner: Stuttgart, Germany, 2003.

43. Reese-Schäfer, W. Soziale Systeme: Grundriß Einer Allgemeinen Theorie. In Klassiker der Sozialwissenschaften; Salzborn, S., Ed.; Springer Fachmedien Wiesbaden: Wiesbaden, Germany, 2016; pp. 350-353. ISBN 978-3-658-13212-5.

44. Steiner, D. Humanökologie: Von Hart zu Weich. Mit Spurensuche bei und mit Peter Weichhart. In Humanökologie: Ansätze zur Überwindung der Natur-Kultur-Dichotomie; Meusburger, P., Schwan, T., Eds.; Steiner: Stuttgart, Germany, 2003; pp. 45-80. ISBN 9783515083775.

45. Weichhart, P. Humanökologie und Geographie. Available online: https://homepage.univie.ac.at/peter. Weichhart/Homepage/Forschung/HumEc/HumecGg.htm (accessed on 19 August 2020).

46. Rayner, A.D.M. Inclusionality and the Role of Place, Space and Dynamic Boundaries in Evolutionary Processes. Philosophica 2004, 73, 51-70.

47. Glaeser, B. Humanökologie und Kulturökologie; Teherani-Krönner, P., Ed.; VS Verlag für Sozialwissenschaften: Wiesbaden, Germany, 1992.

48. Eser, U.; Potthast, T. Naturschutzethik: Eine Einführung für die Praxis, 1; Nomos-Verlag Ges: Baden-Baden, Germany, 1999.

49. Meyer-Abich, K.M. Wege zum Frieden mit der Natur. Prakt. Naturphilosophie für d. Umweltpolitik, Ungekürzte Ausg; Deutscher Taschenbuch-Verlag: München, Germany, 1986. 
50. United Nations for Sustainable Development. Agenda 21. In Proceedings of the United Nations Conference on Evironment and Development, Rio de Janeiro, Brazil, 3-14 June 1992; Available online: https://sustainabledevelopment.un.org/content/documents/Agenda21.pdf (accessed on 19 August 2020).

51. Mizzoni, J.M.; Jardins, J.R.D. Environmental Ethics: An Introduction to Environmental Philosophy, 3rd ed.; Wadsworth: Belmont, CA, USA, 1994.

52. Hendlin, Y.H. Tiefenökologie. In Handbuch Umweltethik; Ott, K., Dierks, J., Voget-Kleschin, L., Eds.; Springer Science and Business Media LLC.: Berlin/Heidelberg, Germany; J.B. Metzler: Stuttgart, Germany, 2016; pp. 195-203.

53. Leopold, A. A Sand County Almanac and Sketches Here and There; Special Commemorative Edition; Oxford University Press: New York, NY, USA, 1989.

54. Philo, C.; Wilbert, C. Animal Spaces, Beastly Places: New Geographies of Human-Animal Relations, 1st ed.; Taylor and Francis: Florence, Italy, 2005.

55. Schweitzer, A. Ehrfurcht vor den Tieren; Grässer, E., Ed.; Durchgesehene Auflage; Beck: München, Germany, 2011.

56. Aerts, R.; Thijs, K.W.; Lehouck, V.; Beentje, H.; Bytebier, B.; Matthysen, E.; Gulinck, H.; Lens, L.; Muys, B. Woody Plant Communities of Isolated Afromontane Cloud Forests in Taita Hills, Kenya. Plant Ecol. 2011, 212, 639-649. [CrossRef]

57. Jaetzold, R.; Schmidt, H.; Hornetz, B.; Shisanya, C. Farm Management Handbook of Kenya: Volume II Natural Conditions and Farm Managemnet Information Part II/C EAST KENYA Subpart C2 Coast Province; Ministry of Agriculture: Nairobi, Kenya, 2012.

58. Maeda, E. Agricultural Expansion and Climate Change in the Taita Hills, KenyA: An Assessment of Potential Environment Impacts; University of Helsinki: Helsinki, Finland, 2011.

59. Platts, P.J.; Ahrends, A.; Gereau, R.E.; McClean, C.J.; Lovett, J.C.; Marshall, A.R.; Pellikka, P.K.E.; Mulligan, M.; Fanning, E.; Marchant, R.; et al. Can Distribution Models Help Refine Inventory-Based Estimates of Conservation Priority? A Case Study in the Eastern Arc Forests of Tanzania and Kenya. Divers. Distrib. 2010, 16, 628-642. [CrossRef]

60. Himberg, N. Traditionally Protected Forests' Role within Transforming Natural Resource Management Regimes in Taita Hills, Kenya; University of Helsinki: Helsinki, Finland, 2011.

61. TTU: University and Campus. Available online: http://www.ttu.ac.ke/ (accessed on 19 August 2020).

62. Corbin, J.; Strauss, A. Basics of Qualitative Research: Techniques and Procedures for Developing Grounded Theory, 4th ed.; SAGE Publications: Thousand Oaks, CA, USA, 2008.

63. Nzau, J.M.; Rogers, R.; Shauri, H.S.; Rieckmann, M.; Habel, J.C. Smallholder Perceptions and Communication Gaps Shape East African Riparian Ecosystems. Biodivers. Conserv. 2018, 27, 3745-3757. [CrossRef]

64. Ritchie, J. Qualitative Research Practice: A Guide for Social Science Students and Researchers, 2nd ed.; SAGE: Los Angeles, NV, USA, 2014.

65. Flick, U. Qualitative Forschung: Theorie, Methoden, Anwendung in Psychologie und Sozialwissenschaften; Orig. Ausg., 5 Aufl.; Rowohlt Verlag: Reinbek bei Hamburg, Germany, 2000.

66. Flick, U. Qualitative Sozialforschung: Eine Einführung; Originalausgabe, 8 Auflage; Rowohlt Verlag: Reinbek bei Hamburg, Germany, 2017.

67. Lüders, C. Beobachtungen im Feld und Ethnografie. In Qualitative Forschung: Ein Handbuch; Flick, U., Kardorff, E.V., Steinke, I., Eds.; 12 Auflage, Originalausgabe; Rowohlt Verlag: Reinbek bei Hamburg, Germany, 2017; pp. 384-401. ISBN 9783499556289.

68. Przyborski, A.; Wohlrab-Sahr, M. Qualitative Sozialforschung; De Gruyter: Berlin, Germany, 2014.

69. Kanitz, J. Das Kopftuch als Visitenkarte; Springer Fachmedien Wiesbaden: Wiesbaden, Germany, 2017.

70. Mayring, P. Einführung in die Qualitative Sozialforschung: Eine Anleitung zu Qualitativem Denken, Überarbeitete Auflage; Beltz: Weinheim, Germany; Basel, Switzerland, 2016.

71. IBM. IBM SPSS Statistics for Windows, Version 25.0. Available online: https://www.ibm.com/us-en/?lnk=m (accessed on 1 March 2019).

72. Bühl, A. SPSS: Einführung in die moderne Datenanalyse ab SPSS 25; Aktualisierte Auflage; Pearson: Hallbergmoos, Germany, 2019.

73. Backhaus, K. Multivariate Analysemethoden: Eine anwendungsorientierte Einführung; Elfte, überarbeitete Aufl.; Springer: Berlin/Heidelberg, Germany, 2006. 
74. Rudolf, M.; Kuhlisch, W. Biostatistik: Eine Einführung für Biowissenschaftler; Pearson Studium: München, Germany; Boston, MA, USA; San Francisco, CA, USA; Harlow, UK, 2008.

75. VERBI Software. MAXQDA Standard, Version 18.1.0. Available online: https://www.maxqda.com/ (accessed on 19 August 2020).

76. Dubois, S.; Fraser, D. Rating Harms to Wildlife: A Survey Showing Convergence Between Conservation and Animal Welfare Views. Anim. Welf. 2013, 22, 49-55. [CrossRef]

77. Zinn, H.C.; Pierce, C.L. Values, Gender, and Concern about Potentially Dangerous Wildlife. Environ. Behav. 2002, 34, 239-256. [CrossRef]

78. Davidson, D.J.; Freudenburg, W.R. Gender and Environmental Risk Concerns. Environ. Behav. 1996, 28, 302-339. [CrossRef]

79. Hoffman, A.J.; Sandelands, L.E. Getting Right with Nature. Organ. Environ. 2005, 18, 141-162. [CrossRef]

80. Matsuzawa, T.; Hockings, K.J.; Humle, T.; Carvalho, S. Chimpanzee Interactions with Nonhuman Species in an Anthropogenic Habitat. Behaviour 2012, 149, 299-324. [CrossRef]

81. McLennan, M.R. Chimpanzee Ecology and Interactions with People in an Unprotected Human-Dominated Landscape at Bulindi, Western Uganda. Ph.D. Thesis, Oxford Brookes University, Oxford, UK, October 2010.

82. Kaltenborn, B.; Bjerke, T.; Nyahongo, J.W.; Williams, D.R. Animal Preferences and Acceptability of Wildlife Management Actions around Serengeti National Park, Tanzania. Biodivers. Conserv. 2006, 15, 4633-4649. [CrossRef]

83. Kuriyan, R. Linking Local Perceptions of Elephants and Conservation: Samburu Pastoralists in Northern Kenya. Soc. Nat. Resour. 2002, 15, 949-957. [CrossRef]

84. Rieckmann, M. Key Themes in Education for Sustainable Development. In Issues and Trends in Education for Sustainable Development; Leicht, A., Heiss, J., Byun, W.J., Eds.; United Nations Educational, Scientific and Cultural Organization: Paris, France, 2018; pp. 61-84. ISBN 978-92-3-100244-1.

85. Sterling, S. The Ecological and Environmental Dimensions of the Holistic Curriculum. In Education for Sustainability; Papagiannis, G., Ed.; Eolss Publishers Co. Ltd.: Oxford, UK, 2009; pp. 309-322. ISBN 9781848265745.

86. Lamarque, F. Human-Wildlife Conflict in Africa: Causes, Consequences and Management Strategies; Food and Agriculture Organization of the United Nations: Rome, Italy, 2009.

87. Republic of Kenya. Forest Conservation and Management Act, 2016: Act No. 34 of 2016. In Kenya Gazette Supplement No. 15; Republic of Kenya Government Printer: Nairobi, Kenya, 2016.

88. Newmark, W.D. Conserving Biodiversity in East African Forests: A Study of the Eastern Arc Mountains; Springer: Berlin/Heidelberg, Germany, 2002.

89. MacArthur, R.H.; Wilson, E.O. The Theory of Island Biogeography; Princeton University Press: Princeton, NJ, USA, 2001.

90. Hohenthal, J.; Räsänen, M.; Owidi, E.; Andersson, B.; Minoia, P.; Pellikka, P.K.E. Community and Institutional Perspectives on Water Management and Environmental Changes in the Taita Hills, Kenya: A Final Research Report. Available online: http://hdl.handle.net/10138/156432 (accessed on 19 August 2020).

91. Mbuvi, M.T.E.; Musyoki, J.K. Impacts of Participatory Forest Management on Community Livelihoods: A Case Study of Dida Community Adjacent to Arabuko-Sokoke Forest in Kilifi County, Kenya. World J. Agric. Sci. 2013, 2, 44-55.

92. VanderMeer, J.; Perfecto, I. Complex Traditions: Intersecting Theoretical Frameworks in Agroecological Research. J. Sustain. Agric. 2012, 24, 44-45. [CrossRef]

93. Habel, J.C.; Weisser, W.W.; Eggermont, H.; Lens, L. Food Security Versus Biodiversity Protection: An Example of Land-Sharing from East Africa. Biodivers. Conserv. 2013, 22, 1553-1555. [CrossRef]

94. Habel, J.C.; Teucher, M.; Mulwa, R.K.; Haber, W.; Eggermont, H.; Lens, L. Nature Conservation at the Edge. Biodivers. Conserv. 2016, 25, 791-799. [CrossRef]

(C) 2020 by the authors. Licensee MDPI, Basel, Switzerland. This article is an open access article distributed under the terms and conditions of the Creative Commons Attribution (CC BY) license (http://creativecommons.org/licenses/by/4.0/). 